\title{
Heterogeneity of cell therapy products
}

\author{
E Wolmarans, ${ }^{1}$ MSc; J Mellet, ${ }^{1}$ MSc; M A Ambele,,${ }^{1,2} \mathrm{PhD} ;$ C Durandt, ${ }^{1} \mathrm{PhD} ;$ M S Pepper, ${ }^{1} \mathrm{MB} \mathrm{ChB}, \mathrm{PhD}, \mathrm{MD}$ \\ ${ }^{1}$ Institute for Cellular and Molecular Medicine, Department of Immunology and South African Medical Research Council Extramural Unit for Stem \\ Cell Research and Therapy, Faculty of Health Sciences, University of Pretoria, South Africa \\ ${ }^{2}$ Department of Oral Pathology and Oral Biology, Faculty of Health Sciences, University of Pretoria, South Africa
}

Corresponding author: M S Pepper (michael.pepper@up.ac.za)

Cellular therapy has become a billion-dollar industry and is set to become one of the therapeutic pillars of healthcare in the 21st century. Adult stem cells, which include haematopoietic stem and progenitor cells (HSPCs) and mesenchymal stromal/stem cells (MSCs), is one of the major cell types currently under investigation for use in cell therapy. This review focuses on HSPCs and MSCs and discusses their heterogeneous nature and the problems faced in expanding these cells to therapeutic numbers for use in clinical applications.

S Afr Med J 2019;109(8 Suppl 1):S25-S29. https://doi.org/10.7196/SAMJ.2019.v3109i8b.13822

Cell therapy entails the administration of living cells that have been purified, propagated or differentiated to create a cell product for a specific therapeutic need. ${ }^{[1]}$ The cell therapy industry initially involved only blood transfusion, haematopoietic stem cell transplantation (HSCT) and reproductive in vitro fertilisation, ${ }^{[2]}$ but has now vastly expanded and will soon be one of the therapeutic pillars of healthcare in the 21st century. ${ }^{[2]}$ Cellular therapies have also diversified over the years and many clinical trials are currently underway (https:// clinicaltrials.gov) to assess the safety and efficacy of various cell types for therapeutic use.

One of the major cell types being investigated for therapeutic use is stem cells. Stem cells can be defined as a population of undifferentiated cells capable of asymmetric replication in which, with each cell division, one of the cells retains its self-renewal capability while the other enters a differentiation pathway and becomes a mature cell. ${ }^{[3-5]}$

Stem cells can broadly be divided into three categories based on their differentiation potential, namely totipotent, pluripotent and multipotent (Fig. 1). Totipotent stem cells refer to cells with the ability to produce all cell types of the human body, including the placenta. Examples include zygotes and early blastomeres. ${ }^{[6]}$ Pluripotent stem cells, which include embryonic stem cells and induced pluripotent stem cells, have the ability to differentiate into cells of the three embryonic germ layers (ectoderm, endoderm and mesoderm) ${ }^{[6,7]}$ In contrast, multipotent (also called adult or somatic) stem cells are able to differentiate into a limited number of cell types, usually associated with the tissue in which they reside. ${ }^{[3,6]}$

Adult stem cells have been identified in various tissues of the human body. Examples include neural stromal/stem cells, endometrial stromal/stem cells, mesenchymal stromal/stem cells (MSCs) and haematopoietic stem and progenitor cells (HSPCs). ${ }^{[4,8]}$ MSCs have been isolated from bone marrow, the umbilical cord, adipose tissue and dental pulp. ${ }^{[9,10]}$ The main sources of HSPCs are bone marrow, umbilical cord blood (UCB) and mobilised peripheral blood.

HSPCs and MSCs are two of the most extensively studied adult stem cells in research and clinical settings. In this review we discuss the heterogeneous nature of HSPCs and MSCs as well as some of the problems associated with the expansion of these cells for use in therapeutic products in various clinical applications.

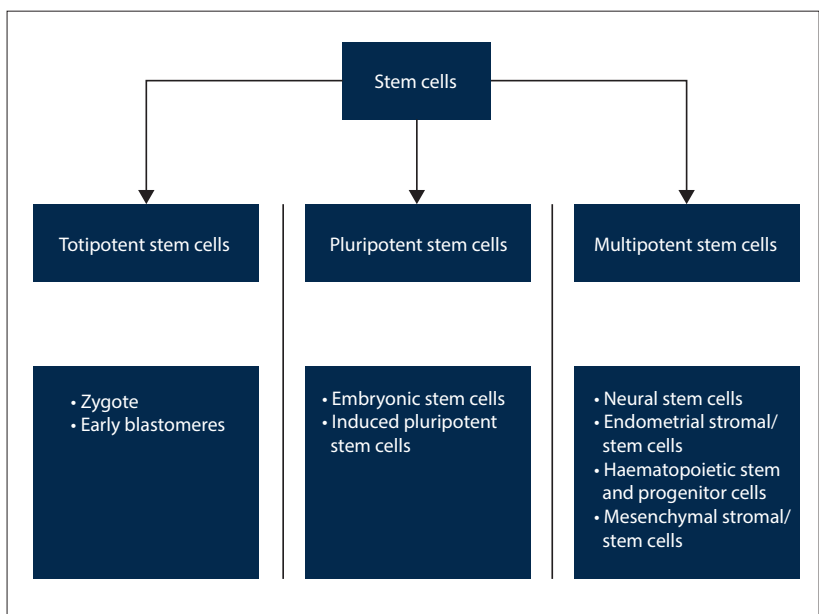

Fig. 1. Schematic diagram of the different categories of stem cell.

\section{Heterogeneity}

Adult stem cells exist in a tightly regulated microenvironment (referred to as a niche) and are dispersed between differentiated cells in various tissues in the body. ${ }^{[11]}$ As a result, the isolated cells are a heterogeneous population, consisting of various subpopulations, including a subpopulation of true stem cells. To date, there is no single phenotypic marker that can unambiguously identify a true stem cell. Thus, currently used therapeutic stem cell products are heterogeneous in nature.

Another aspect of heterogeneity relates to differences seen between primary cultures. Primary cultures can vary with regard to their morphology and immunophenotype, depending on, among other factors, species, individual, the site of isolation, age of the patient and the downstream processing of the cells. ${ }^{[12]}$

Cellular heterogeneity has an important role in many biological processes and can be either an advantage or a hindrance in the research and clinical setting.

\section{Haematopoietic stem and progenitor cells}

HSPCs are capable of self-renewal and can differentiate into any of the lineages of the haematopoietic system. HSCT is a well-established 
form of treatment for haematological disorders, including malignancies such as myeloma, lymphoma and leukaemia. In this setting, autologous or allogeneic transplants are performed to reconstitute the entire haematopoietic system after chemotherapy. A global survey by the Worldwide Network for Blood and Marrow Transplantation Group showed that the number of transplants (autologous and allogeneic) increased by $46 \%$ between 2006 and 2012 across 77 countries, with 46563 transplants performed in 2006 (20 333 allogeneic; 26230 autologous) and 68146 in 2012 (31 926 allogeneic; 36220 autologous). ${ }^{[13]}$ Transplants from matched, unrelated donors managed by the World Marrow Donor Association showed an increase from 7503 allogeneic transplants in 2006 to 17413 in 2012 and 21257 in 2017. ${ }^{[14]}$ Both reports ${ }^{[13,14]}$ show that mobolised periheral blood products have become the predominant source of HSPCs compared with bone marrow and UCB. Limited data exist on HSCT in the South African (SA) context. Global surveys show a 90\% increase overall in HSCT in the World Health Organization (WHO)'s African and Eastern Mediterranean regions from 2006 to 2013 , with a $69 \%$ and $129 \%$ increase in allogeneic and autologous transplants, respectively. ${ }^{[15]}$

The CD34 cell surface marker is primarily used to identify, isolate and enumerate HSPCs. ${ }^{[16]}$ Isolated $\mathrm{CD} 34^{+}$HSPCs are a heterogeneous population, which includes both primitive haematopoietic stem cells (HSCs) and early- and late-stage progenitors (Fig. 2). The pool of self-renewing HSCs has both long- and short-term repopulating potential, with long-term HSCs capable of self-renewal throughout life. In contrast, short-term HSCs have only limited selfrenewal capabilities. Short-term HSCs give rise to multipotent progenitors, which are precursors of common lymphoid and myeloid progenitors (CLP/CMP) but which have no self-renewal abilities. CLP progeny differentiate into lymphoid and natural killer (NK) cells. CMP progeny differentiate into granulocyte-macrophage progenitors and megakaryocyte-erythroid progenitors, which will differentiate into granulocytes and macrophages, and erythrocytes and megakaryocytes, respectively. ${ }^{[17]}$ Heterogeneity of the $\mathrm{CD} 34^{+}$population is considered an advantage in HSCT as it ensures both shortand long-term engraftment.

$\mathrm{CD} 34^{+}$cell count is generally used as a predictor of engraftment following HSCT. ${ }^{[18]}$ The optimal $\mathrm{CD}_{3} 4^{+}$cell dose should be $2.0-5.0 \times 10^{6} / \mathrm{kg}$ body weight for full

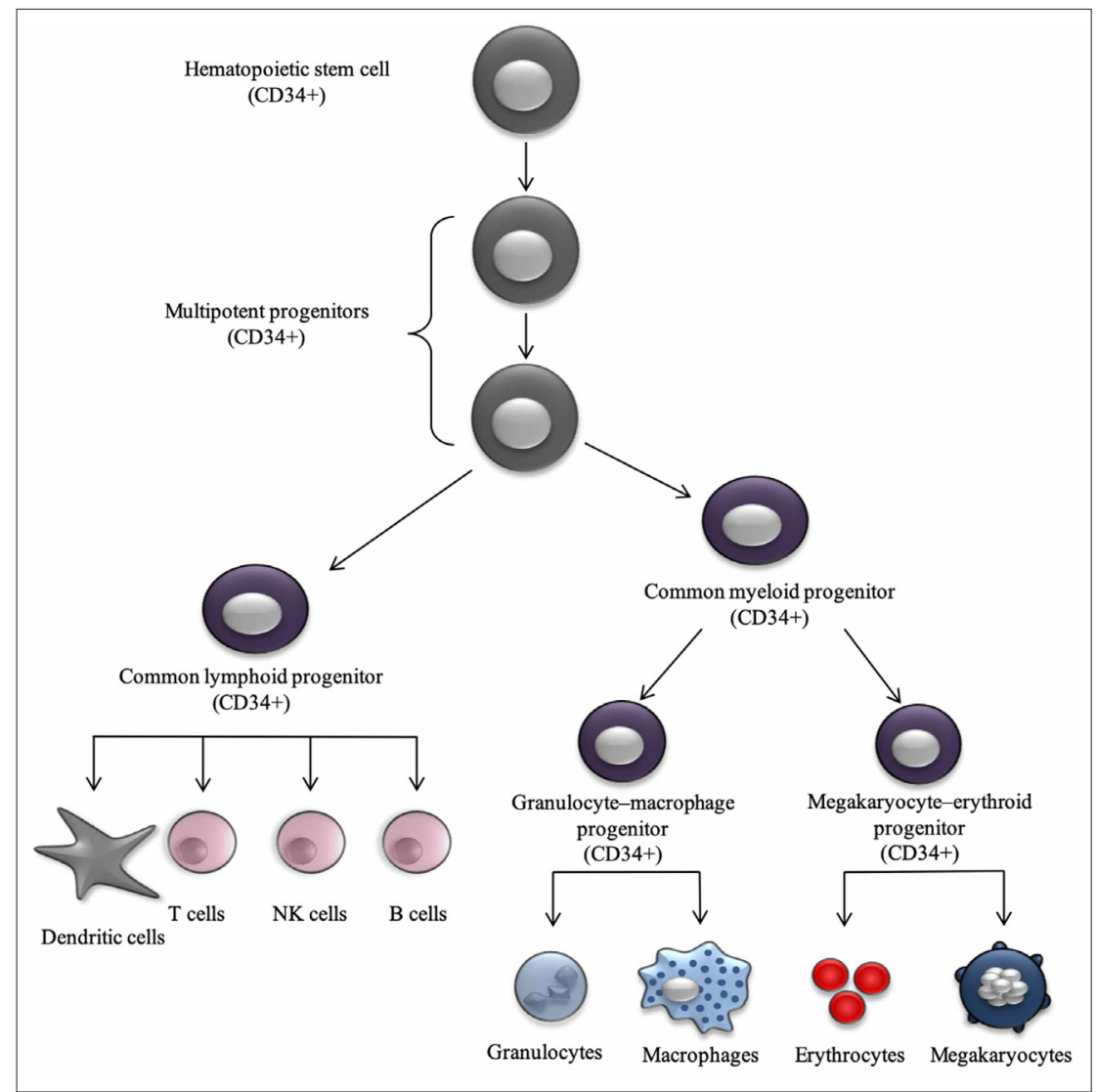

Fig. 2. Diagram of the haematopoietic hierarchy, showing all the subpopulations of cells that are CD34+ (NK = natural killer. $)$

haematopoietic recovery ${ }^{[19]}$ Several studies have shown that an increase in the number of total nucleated cells and $\mathrm{CD} 34^{+}$cells leads to improved engraftment in transplant recipients. ${ }^{[20]}$ In contrast, lower cell numbers pose the risk of delayed haematopoietic recovery, which could potentially increase the risk of infection and necessitate patient hospitalisation following HSCT. One way to eliminate this adverse effect is through ex vivo expansion to increase HSPCs to clinically relevant numbers prior to transplantation.

Expansion of HSPCs has been an area of interest for several years, especially given the difficulty in maintaining stem cell capabilities during this process. HSPC culture conditions induce spontaneous differentiation and loss of specific stem cell markers such as CD34 and CD133. Concerns regarding the effects of expansion have led to the coadministration of non-expanded and ex vivo expanded units during HSCT. ${ }^{[21-23]}$

Ex vivo expansion of HSPCs has been achieved though different culturing methods at different times and with the addition of a variety of compounds. Cytokines were some of the first compounds used to expand HSPCs ex vivo. A major breakthrough was achieved when a purine derivative, StemRegenin 1 (SR-1), was found to promote ex vivo expansion of $\mathrm{CD}_{3} 4^{+} \mathrm{HSPCs}$ derived from human UCB 50-fold and induced a 17 -fold increase in the number of human HSPCs engrafting long term in immunodeficient mice. ${ }^{[24]} \mathrm{A}$ recent clinical study demonstrated improved engraftment in human recipients of UCB-derived CD34 ${ }^{+}$HSPCs expanded ex vivo with SR-1 compared with recovery in recipients who received equal numbers of $\mathrm{CD} 34^{+}$cells from the same unit but that were not expanded ex vivo. ${ }^{[22]}$ Another study has shown that a pyrimidoindole derivative, UM171, also induces human HSPC selfrenewal and expansion ex vivo. Use of UM171 resulted in improved expansion of the more primitive human $\mathrm{CD} 34^{+}$cells from mobilised peripheral blood. ${ }^{[25]}$ UM171 and SR-1 may therefore represent promising chemical compounds for ex vivo expansion of human HSPCs for clinical applications.

\section{Mesenchymal stromal/ stem cells}

MSCs are adult stem/stromal cells that can be isolated from numerous tissues in 
the human body. The International Society for Cellular Therapy established minimum criteria for cells to be classified as MSCs, including: adherence to uncoated plastic culture dishes under standard culture conditions; the ability of the cells to differentiate into osteoblasts, adipocytes and chondrocytes in vitro, and a specific phenotypic antigen expression profile. ${ }^{[26]}$

It is important to note that MSCs isolated and expanded in culture, irrespective of the tissue of isolation, are a heterogeneous population of cells. Surface antigen markers are not expressed exclusively on one cell type and therefore the specified phenotype does not reflect a homogeneous cell population, but rather a heterogeneous population of cells that share a similar phenotypic profile.

The two best studied and most widely used sources of MSCs are bone marrow ${ }^{[27]}$ and adipose tissue. ${ }^{[28]}$ MSCs derived from bone marrow (BM-MSCs) and adipose-derived stromal/stem cells (ASCs) are morphologically similar, ${ }^{[9,29]}$ but differ slightly in their immunophenotypic profiles; ${ }^{[30]}$ some of the cell surface proteins that are differentially expressed include CD10 (metallo-endopeptidase) and CD36 (fatty acid translocase). ${ }^{[30]}$ Differences between the transcriptome profiles of these two cell types are more pronounced. ${ }^{[9]}$ Despite their transcriptomic and immunophenotypic differences, both cell types were shown to have the ability to differentiate into osteocytes, adipocytes and chondrocytes. ${ }^{[9,29]}$ However, ASCs showed a greater potential for adipogenesis and chondrogenesis than BM-MSCs and have also been reported to proliferate more rapidly. ${ }^{[29]}$ Another advantage of ASCs over BM-MSCs is that they are abundant and easily accessible: per gram of tissue, up to 500 times more MSCs can be isolated from adipose tissue than from bone marrow. ${ }^{[31]}$

MSCs have shown great potential in the fields of regenerative medicine and tissue repair. It is believed that the clinical benefit of MSCs lies not only in their ability to differentiate into specific cell types, but also in their interactions with other cells via paracrine signalling. ${ }^{[32]}$ MSCs secrete a mixture of angiogenic, anti-inflammatory and anti-apoptotic cytokines. ${ }^{[33,34]}$ The complex interplay of the various biological molecules secreted by MSCs causes the recruitment of other cells, which assists with the healing process. ${ }^{[35,36]}$ MSCs have furthermore also been shown to have immunomodulatory effects through suppressing the proliferation and functions of T, B, NK and dendritic cells. ${ }^{[37,38]}$

A basic search of clinical trials with either BM-MSCs or ASCs between 2000 and 2019 yielded 239 studies worldwide (https:// clinicaltrials.gov). These include studies that have been completed, are currently active or are currently recruiting donors or volunteers.
Studies that have been suspended, terminated or withdrawn were not considered in our search. Of the 239 studies, 121 involve the use of BM-MSCs and 118 involve the use of ASCs. The conditions being treated in these clinical trials are diverse; the most common conditions treated with BM-MSCs and/or ASCs in these trials are listed in Table 1 .

To our knowledge, only two licensed MSC-based products are available. One is Prochymal, which consists of cultured BM-MSCs that have been cryopreserved. It was tested by Osiris Therapeutics (USA) in a phase III clinical trial for patients with steroid-refractory graft-versus-host disease (GVHD) in 2009. ${ }^{[39,40]}$ Health Canada subsequently approved the drug via a Notice of Compliance with Conditions. ${ }^{[39]}$ However, Prochymal has not been distributed outside of clinical trials since its approval and has not been marketed as a treatment for steroid-refractory GVHD. ${ }^{[39]}$ The other is Alofisel (designed by Takeda, USA), which was approved by the European Commission in 2018. Alofisel consists of allogeneic-cultured ASCs that have been cryopreserved and is used to treat enterocutaneous fistulae in Crohn's disease. ${ }^{[39,41]}$

Although MSCs have great potential and are being considered as a potential therapeutic product for a number of diseases, considerable further research is needed before MSCs can be used with confidence in the clinical setting. A great deal of effort is being made to better understand the heterogeneous nature of the isolated cell populations and how this heterogeneity contributes to or impedes possible clinical benefit. For example, many clinical trials currently using ASCs administer the stromal vascular fraction (SVF), which involves the highly heterogeneous cellular component extracted from adipose tissue (excluding mature adipocytes) being injected into the patient without culturing. As shown in Fig. 3, the SVF consists of HSPCs, endothelial precursor cells, endothelial cells, macrophages, smoothmuscle cells, lymphocytes, erythrocytes, pericytes and pre-adipocytes, among others. ${ }^{[30]}$

The preferential use of the SVF in clinical trials is based largely on the US Food and Drug Administration's view that cultured cells are considered to be a more manipulated cell therapy product. However, heterogeneity in these cellular populations may be a hindrance. From a research perspective, heterogeneity of the starting cell populations can increase experimental variability. This contributes to variable research data and may prevent reproducing reported results. ${ }^{[42]}$ From a clinical point of view, the absence of specific markers for stem cells limits our ability to determine the purity of a therapeutic MSC product. It is hypothesised that cellular heterogeneity could decrease the

Table 1: Most common conditions treated with mesenchymal stromal/stem cells derived from bone marrow or adipose-derived stromal/stem cells in clinical trials, 2000 - 2019

\begin{tabular}{ll}
\hline Condition & Cell type \\
\hline Chron's disease and Chron's fistula & Both \\
Osteoarthritis & Both \\
Critical limb ischaemia & Both \\
Myocardial infarction & Both \\
Erectile dysfunction & Both \\
Spinal cord injury & Both \\
Amyotrophic lateral sclerosis & BM-MSCs \\
Graft-versus-host disease (GVHD) & BM-MSCs \\
Multiple sclerosis & BM-MSCs \\
Fat grafts for reconstructive surgery & ASCs \\
Chronic ischaemic heart disease & ASCs \\
Chronic obstructive pulmonary disease & ASCs
\end{tabular}




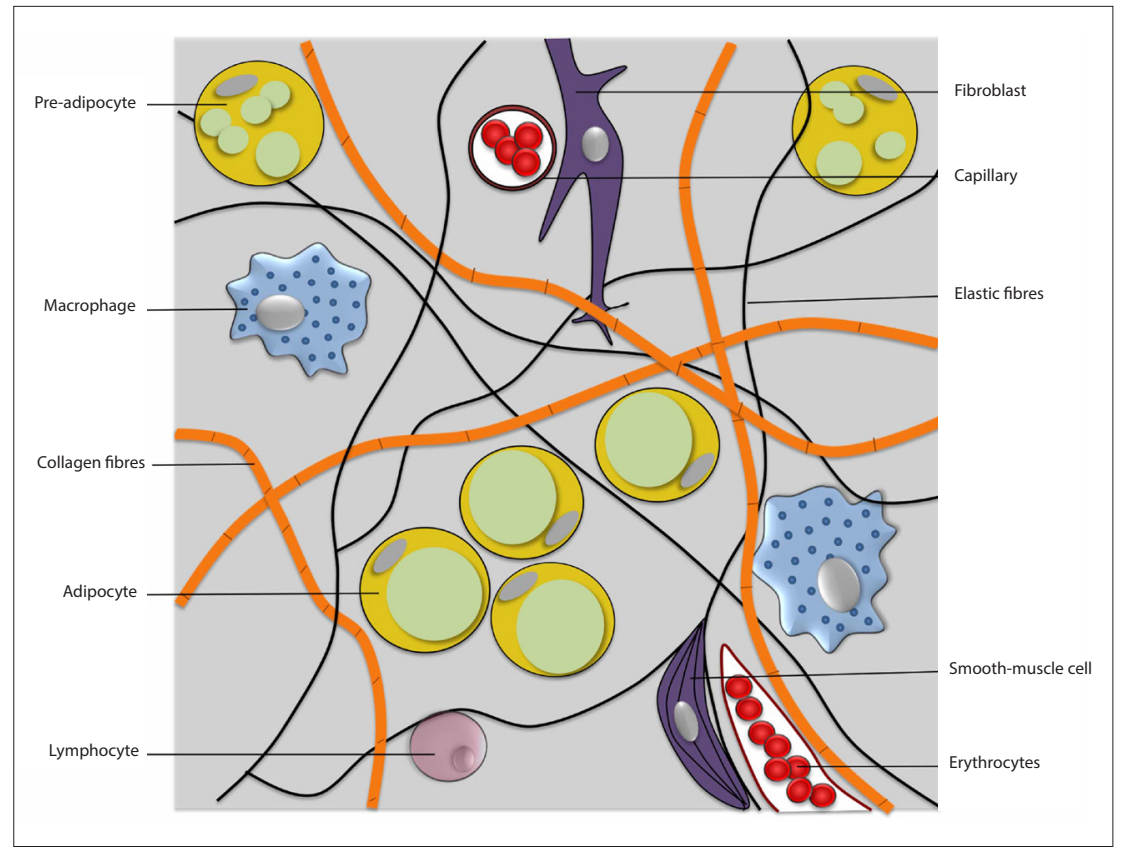

Fig. 3. Illustration of various cell types present in adipose tissue.

number of functional progenitors delivered to diseased tissue, thus reducing treatment efficacy ${ }^{[43]}$ It is further hypothesised that a better understanding of heterogeneity may allow unwanted cells to be removed from heterogeneous populations or facilitate the optimum composition of cells for improved therapeutic efficacy to be determined. ${ }^{[31,43]}$

Both in vitro and in vivo studies have shown that by purifying the MSC population using techniques such as the side population assay, ${ }^{[44]}$ immunophenotypic characterisation or single-cell transcriptome analysis, ${ }^{[43,45]}$ the resulting subpopulations show greater stemness than the original, heterogeneous population. Using single-cell transcriptome technology, two research groups have independently identified a subpopulation of cells at the phenotypic level, based on the expression of the marker CD55. The one group found increased expression of genes related to survival, stemness and tissue remodelling in this subpopulation, ${ }^{[43]}$ while the other team found their $\mathrm{CD} 55^{+}$ subpopulation to have higher adipogenic differentiation capacity in vitro than the other subpopulations studied. ${ }^{[45]}$ To our knowledge, purified subpopulations of MSCs have not yet been used in a clinical trial.

Certain clinical applications will require ex vivo expansion of MSCs to achieve clinically relevant cell numbers, which carries a risk of selecting for specific clones. The issue of clonal selection has been well documented ${ }^{[46-49]}$ and it has been shown that specific clones predominate at different stages during the expansion process. ${ }^{[46,49]}$ These so-called transiently contributing clones have varied phenotypic characteristics, which could influence the therapeutic efficacy of ex vivo expanded cells. Continuous expansion of a heterogeneous cell population reduces cell heterogeneity considerably and selects for single clones over time, ${ }^{[46]}$ which can either be beneficial or limiting with regard to their therapeutic effect. At present, clonal selection cannot be controlled; therefore, the ever-changing clonal composition of MSC cultures over time during ex vivo expansion requires careful consideration of the cell culture passage number at which they are to be used for treatment purposes. Ideally, the number of ex vivo expansion rounds should be kept to a minimum to reduce clonal selection and other changes induced in the cell therapy product.

The expansion of MSCs for clinical application requires that the isolation and handling procedures of the cells be compliant with good manufacturing practice. In most countries and jurisdictions, the use of cellular products for cell therapy is regulated by governmental agencies. The International Society for Stem Cell Research further published guidelines for stem cell science and clinical translation, which recommend that all reagents and processes should be subjected to quality-control systems and standard operation procedures during the manufacture of the cell therapy product. Animal-derived components used in the culture and preservation of cells should be replaced with human or chemically defined components. Lastly, release criteria for the cell product should be designed to minimise the risk from culture-acquired abnormalities such as karyotypic instabilities. ${ }^{[50]}$

An additional aspect under investigation is the potential of MSCs to promote tumour growth. There are numerous contradictory studies, with some reporting that MSCs promote tumour growth while others report an inhibiting effect. Readers are referred to concise reviews on this topic by Klopp et al. ${ }^{[38]}$ and Oloyo et al. ${ }^{[51]}$

\section{Conclusion}

HSPCs and MSCs are heterogeneous populations that have been used successfully for many years (HSPCs) or have recently shown great potential (MSCs) in the field of cell therapy. The heterogeneous nature of HSPCs, as a standard therapeutic cell product in HSCT, is believed to be beneficial, as the various subpopulations facilitate both shortand long-term engraftment in the patient.

Although MSC-based therapies are still experimental, clinical trials suggest the safety and potential efficacy of these cells as a cell therapy product for a wide range of diseases. However, there is still much to be investigated before MSCs can be used with confidence in the clinical setting. To our knowledge, all clinical trials thus far have been conducted using heterogeneous populations of cells. A great deal of effort is being made to better understand the heterogeneous nature of the isolated cell populations, so as to reduce experimental variability and clonal selection in MSCs grown ex vivo. It is also hypothesised that heterogeneity could decrease the number of functional progenitors delivered to diseased tissue, thus reducing treatment efficacy. ${ }^{[43]}$ Strategies to isolate, purify and propagate subpopulations of adult stem cells may, therefore, contribute to the development of cell therapy products with enhanced clinical benefit in future.

\section{Acknowledgements. None.}

Author contributions. EW wrote the first draft and all authors subsequently contributed substantially to the manuscript. MSP conceptualised the review and approved the final version.

Funding. This research was funded by the South African Medical Research Council (SAMRC) under its Flagship Award Project (SAMRC-RFA-UFSP-01-2013/STEM CELLS), the SAMRC Extramural Unit for Stem Cell Research and Therapy and the Institute for Cellular and Molecular Medicine of the University of Pretoria.

Conflicts of interest. None. 
1. Mount NM, Ward SJ, Kefalas P, Hyllner J. Cell-based therapy technology classifications and translational challenges. Philos Trans R Soc Lond B Biol Sci 2015;370(1680):20150017. https://doi. translational challenges. Ph
org/10.1098/rstb.2015.0017

2. Mason C, Brindley DA, Culme-Seymour EJ, Davie NL. Cell therapy industry: Billion dollar global business with unlimited potential. Regen Med 2011;6(3):265-272. https://doi.org/10.2217//rme.11.28 3. Cha J, Falanga V. Stem cells in cutaneous wound healing. Clin Dermatol 2007;25(1):73-78. https://doi. org/10.1016/j.clindermatol.2006.10.002

4. Blau HM, Brazelton TR, Weimann JM. The evolving concept of a stem cell: Entity or function? Cell 2001;105(7):829-841. https://doi.org/10.1016/S0092-8674(01)00409-3

5. Ramos CA, Venezia TA, Camargo FA, Goodell MA. Review techniques for the study of adult stem cells: Be fruitful and multiply. Biotechniques 2003;34(3):572-591. https://doi.org/10.2144/03343rv01

6. Daley GQ. Stem cells and the evolving notion of cellular identity. Phil Trans R Soc Lond B Biol Sci 2015;370(1680):20140376. https://doi.org/10.1098/rstb.2014.0376

7. Mora C, Serznati M, Consiglio A, Memo M, Dell'Era P. Clinical potentials of human pluripotent stem cells. Cell Biol Toxicol 2017;33(4):351-360. https://doi.org/10.1007/s10565-017-9384-y

8. Gargett CE, Schwab KE, Deane JA. Endometrial stem/progenitor cells: The first 10 years. Hum Reprod Update 2016;22(2):137-163. https://doi.org/10.1093/humupd/dmv051

9. Wagner W, Wein F, Seckinger A, et al. Comparative characteristics of mesenchymal stem cells from human bone marrow, adipose tissue, and umbilical cord blood. Exp Hematol 2005;33(11):1402-1416. https://doi.org/10.1016/j.exphem.2005.07.003

10. Kawashima N. Characterisation of dental pulp stem cells: A new horizon for tissue regeneration? Arch Oral Biol 2012;57(11):1439-1458. https://doi.org/10.1016/j.archoralbio.2012.08.010

11. Lin T, Islam O, Heese K. ABC transporters, neural stem cells and neurogenesis - a different perspective. Cell Res 2006;16(11):857-871. https://doi.org/10.1038/sj.cr.7310107

12. Ong WK, Tan CS, Chan KL, et al. Identification of specific cell-surface markers of adipose-derived stem cells from subcutaneous and visceral fat depots. Stem Cell Reports 2014;2(2):171-179. https://doi. org/10.1016/j.stemcr.2014.01.002

13. Niederwieser D, Baldomero H, Szer J, et al. Hematopoietic stem cell transplantation activity worldwide in 2012 and a SWOT analysis of the Worldwide Network for Blood and Marrow Transplantation Group including the global survey. Bone Marrow Transplant 2016;51(6):778-785. https://doi.org/10.1038/ including the
bmt.2016.18

14. World Marrow Donor Association. World Marrow Donor Association Global Trend Report Netherlands: WMDA, 2017. https://www.wmda.info/wp-content/uploads/2018/06/20180531-GTRGraphs-2017-Summary (accessed 20 January 2019).

15. Baldomero H, Aljurf M, Zaidi SZA, et al. Narrowing the gap for hematopoietic stem cell transplantation in the East-Mediterranean/African region: Comparison with global HSCT indications and trends. Bone Marrow Transplant 2019;54(3):402-417. https://doi.org/10.1038/s41409-018-0275-5

16. Lemos NE, Farias MG, Kubaski F, et al. Quantification of peripheral blood CD34+ cells prior to stem cell harvesting by leukapheresis: A single center experience. Hematol Transfus Cell Ther 2018;40(3):213-218. https://doi.org/10.1016/j.htct.2018.01.002

17. Kondo M. Lymphoid and myeloid lineage commitment in multipotent hematopoietic progenitors. Immunol Rev 2010;238(1):37-46. https://doi.org/10.1111/j.1600-065X.2010.00963.X

18. Bai L, Xia W, Wong K, Reid C, Ward C, Greenwood M. Factors predicting haematopoietic recovery in patients undergoing autologous transplantation: 11 -year experience from a single centre. Ann Hematol patients undergoing autologous transplantation: 11-year experience
2014;93(10):1655-1664. https://doi.org/10.1007/s00277-014-2112-2

19. Wuchter P, Ran D, Bruckner T, et al. Poor mobilization of hematopoietic stem cells - definitions, incidence, risk factors, and impact on outcome of autologous transplantation. Biol Blood Marrow Transplant 2010;16(4):490-499. https://doi.org/10.1016/j.bbmt.2009.11.012

20. Gómez-Almaguer D, Gómez-Peña Á, Jaime-Pérez JC, et al. Higher doses of CD34+ progenitors are associated with improved overall survival without increasing GVHD in reduced intensity conditioning allogeneic transplant recipients with clinically advanced disease. J Clin Apher 2013;28(5):349-355. https://doi.org/10.1002/jca.21278

21. Horwitz ME, Chao NJ, Rizzieri DA, et al. Umbilical cord blood expansion with nicotinamide provides long-term multilineage engraftment. J Clin Invest 2014;124(7):3121-3128. https://doi.org/10.1172/ JCI74556

22. Wagner JE Jr, Brunstein CG, Boitano AE, et al. Phase I/II trial of StemRegenin-1 expanded umbilical cord blood hematopoietic stem cells supports testing as a stand-alone graft. Cell Stem Cell 2016;18(1):144-155. https://doi.org/10.1016/..stem.2015.10.004

23. Anand S, Thomas S, Hyslop T, et al. Transplantation of ex vivo expanded umbilical cord blood (NiCord) decreases early infection and hospitalization. Biol Blood Marrow Transplant 2017;23(7):1151-1157. decreases early infection and hospitalization
https://doi.org/10.1016/j.bbmt.2017.04.001

24. Boitano AE, Wang J, Romeo R, et al. Aryl hydrocarbon receptor antagonists promote the expansion of human hematopoietic stem cells. Science 2010;329(5997):1345-1348. https://doi.org/10.1126/ science. 1191536

25. Fares I, Chagraoui J, Gareau Y, et al. Cord blood expansion. Pyrimidoindole derivatives are agonists of human hematopoietic stem cell self-renewal. Science 2014;345(6203):1509-1512. https://doi. org/10.1126/science.1256337

26. Dominici M, Le Blanc K, Mueller I, et al. Minimal criteria for defining multipotent mesenchymal stromal cells. The International Society for Cellular Therapy position statement. Cytotherapy 2006;8(4):315-317. https://doi.org/10.1080/14653240600855905
27. Lennon DP, Caplan AI. Isolation of human marrow-derived mesenchymal stem cells. Exp Hematol 2006;34(11):1604-1605. https://doi.org/10.1016/j.exphem.2006.07.014

28. Van Vollenstee FA, Dessels C, Kallmeyer K, et al. Isolation and characterization of adipose-derived Van Vollenstee FA, Dessels C, Kallmeyer K, et al. Isolation and characterization of adipose-derived
stromal cells. In: Pham P, (ed). Stem Cell Processing. Stem Cells in Clinical Applications. Switzerland, Springer, 2016:131-161. https://doi.org/10.1007/978-3-319-40073-0

29. Li X, Bai J, Ji X, Li R, Xuan Y, Wang Y. Comprehensive characterization of four different populations of human mesenchymal stem cells as regards their immune properties, proliferation and differentiation. Int J Mol Med 2014;34(3):695-704. https://doi.org/10.3892/ijmm.2014.182

30. Bourin P, Bunnell BA, Casteilla L, et al. Stromal cells from the adipose tissue-derived stroma vascular fraction and culture expanded adipose tissue-derived stromal/stem cells: A joint statement of the International Federation for Adipose Therapeutics and Science (IFATS) and the Internationa Society for Cellular Therapy (ISCT). Cytotherapy 2013;15(6):641-648. https://doi.org/10.1016/j. jcyt.2013.02.006

31. Bora P, Majumdar AS. Adipose tissue-derived stromal vascular fraction in regenerative medicine: A brief review on biology and translation. Stem Cell Res Ther 2017;8:145-155. https://doi.org/10.1186 s13287-017-0598-y

32. Hassan WU, Greiser U, Wang W. Role of adipose-derived stem cells in wound healing. Wound Repair Regen 2014;22(3):313-325. https://doi.org/10.1111/wrr.12173

33. Baer PC, Geiger H. Adipose-derived mesenchymal stromal/stem cells: Tissue localization, characterization, and heterogeneity. Stem Cells Int 2012;2012:812693. https://doi org $/ 10.1155 / 2012 / 812693$

34. Rubio-Azpeitia E, Andia I. Partnership between platelet-rich plasma and mesenchymal stem cells: In vitro experience. Muscles Ligaments Tendons I 2014;4(1):52-62. https://doi.org/10.11138 mltij/2014.4.1.052

35. Bansal $\mathrm{H}$, Comella K, Leon J, et al. Intra-articular injection in the knee of adipose derived stromal cell (stromal vascular fraction) and platelet rich plasma for osteoarthritis. Transl Med 2017;15:141-152. https://doi.org/10.1186/s12967-017-1242-4

36. Otero-Viñas M, Falanga V. Mesenchymal stem cells in chronic wounds: The spectrum from basic to advanced therapy. Adv Wound Care 2016;5(4):149-163. https://doi.org/10.1089/wound.2015.0627

37. Hass R, Kasper C, Böhm S, Jacobs R. Different populations and sources of human mesenchym stem cells (MSC): A comparison of adult and neonatal tissue-derived MSC. Cell Commun Signal 2011;9(1):12-26. https://doi.org/10.1186/1478-811X-9-12

38. Klopp AH, Gupta A, Spaeth E, Andreeff M, Marini F. Concise review: Dissecting a discrepancy in the literature: Do mesenchymal stem cells support or suppress tumor growth? Stem Cells 2011:29(1):1119. https://doi.org/10.1002/stem.559

39. Galipeau J, Sensébé L. Mesenchymal stromal cells: Clinical challenges and therapeutic opportunities. Cell Stem Cell 2018;22(6):824-833. https://doi.org/10.1016/j.stem.2018.05.004

40. Kebriaei P, Isola L, Bahceci E, et al. Adult human mesenchymal stem cells added to corticosteroid

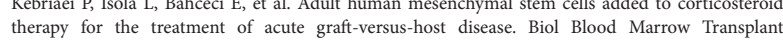
2009:15(7):804-811. https://doi.org/10.1016/j.bbmt.2008.03.012

41. Panés J, García-Olmo D, Van Assche G, et al. Expanded allogeneic adipose-derived mesenchymal stem cells (Cx601) for complex perianal fistulas in Crohn's disease: A phase 3 randomised, double-blin controlled trial. Lancet 2016;388(10051):1281-1290. https://doi.org/10.1016/S0140-6736(16)31203-X

42. Mo M, Wang S, Zhou Y, Li H, Wu Y. Mesenchymal stem cell subpopulations: Phenotype, propert and therapeutic potential. Cell Mol Life Sci 2016;73(17):3311-3321. https://doi.org/10.1007/s00018 016-2229-7

43. Rennert RC, Januszyk M, Sorkin M, et al. Microfluidic single-cell transcriptional analysis rationally identifies novel surface marker profiles to enhance cell-based therapies. Nat Commun 2016;7:1194511954. https://doi.org/10.1038/ncomms11945

44. Wolmarans E, Nel S, Durandt C, Mellet J, Pepper M. Side population: Its use in the study of cellular heterogeneity and as a potential enrichment tool for rare cell populations. Stem Cells Int 2018:2472137. https://doi.org/10.1155/2018/2472137

45. Schwalie PC, Dong H, Zachara M, et al. A stromal cell population that inhibits adipogenesis in mammalian fat depots. Nature 2018;559(7712):103-108. https://doi.org/10.1038/s41586-018-0226-8

46. Selich A, Daudert J, Hass R, et al. Massive clonal selection and transiently contributing clones during expansion of mesenchymal stem cell cultures revealed by lentiviral RGB-barcode technology. Stem expansion of mesenchymal stem cell cultures revealed by lentiviral RGB-baco
Cells Transl Med 2016;5(5):591-601. https://doi.org/10.5966/sctm.2015-0176

47. Bogdan P, Deasy BM, Gharaibeh B, Roehrs T, Marculescu R. Heterogeneous structure of stem cell dynamics: Statistical models and quantitative predictions. Sci Rep 2014;4:4826-4837. https://doi. org/10.1038/srep04826

48. Cai J, Miao X, Li Y, et al. Whole-genome sequencing identifies genetic variances in culture-expande human mesenchymal stem cells. Stem Cell Reports 2014;3(2):227-233. https://doi.org/10.1016/j stemcr.2014.05.019

49. Liu Y, Muñoz N, Bunnell BA, Logan TM, Ma T. Density-dependent metabolic heterogeneity in huma mesenchymal stem cells. Stem Cells 2015;33(11):3368-3381. https://doi.org/10.1002/stem.2097

50. International Society for Stem Cell Research. Guidelines for stem cell science and clinical translation. USA: ISSCR, 2016. https://www.isscr.org/docs/default-source/all-isscr-guidelines/guidelines-2016 isscr-guidelines-for-stem-cell-research-and-clinical-translation (accessed 19 January 2019).

51. Oloyo AK, Ambele MA, Pepper MS. Contrasting views on the role of mesenchymal stromal/stem cells in tumour growth: A systematic review of experimental design. Adv Exp Med Biol 2018;1083:103-124. https://doi.org/10.1007/5584_2017_118 